\title{
MODELING ROMAN PAVEMENTS USING HERITAGE-BIM: A CASE STUDY IN POMPEII
}

\section{SALVATORE ANTONIO BIANCARDO ${ }^{1 *}$, FRANCESCA RUSSO ${ }^{2}$, ROSA VEROPALUMBO ${ }^{3}$, VIKTORAS VOROBJOVAS ${ }^{4}$, GIANLUCA DELL'ACQUA ${ }^{5}$ \\ ${ }^{1-3,5}$ Dept of Civil, Construction and Environmental Engineering, Federico II University of Naples, Naples, Italy \\ ${ }^{4}$ Dept of Roads, Vilnius Gediminas Technical University, Vilnius, Lithuania}

Received 10 February 2020; accepted 3 June 2020

\begin{abstract}
The study of ancient stone pavements represents the necessary premise for planning and execution of treatments that considers the necessity of conservation. The approach to the integrated management of information derived through H-BIM has been applied to Via del Vesuvio, one of the main roads in the archaeological site of Pompeii in Naples, Italy. The digital terrain model was carried out using Autodesk Infraworks software. Then, using Autodesk Civil 3D and Revit software, the road was digitalized creating the 3D model that included road geometric information resulting from an on-site survey, material characteristics for each pavement layer, construction period and related construction cost information. Finally, based on the existing research works available in the literature review, using Autodesk Naviswork software, it was possible to implement in the 3D model the BIM fourth
\end{abstract}

* Corresponding author. E-mail: salvatoreantonio.biancardo@unina.it

Salvatore Antonio BIANCARDO (ORCID ID 0000-0003-2567-7977)

Francesca RUSSO (ORCID ID 0000-0003-0677-9433)

Rosa VEROPALUMBO (ORCID ID 0000-0002-7035-7967)

Viktoras VOROBJOVAS (ORCID ID 0000-0001-9420-0668)

Gianluca DELL'ACQUA (ORCID ID 0000-0001-8697-7477)

Copyright (C) 2020 The Author(s). Published by RTU Press

This is an Open Access article distributed under the terms of the Creative Commons Attribution License (http://creativecommons.org/licenses/by/4.0/), which permits unrestricted use,

distribution, and reproduction in any medium, provided the original author and source are credited. 
dimension, namely, the time related to the construction of Via Del Vesuvio Rosa Veropalumbo, in different eras. The interoperability between the adopted BIM authoring software was exploited. The adopted procedure can be considered a benchmark case in the technical literature of H-BIM for stone pavements, highlighting the advantages in the design field.

Keywords: 4D time dimension, Heritage-Building Information Modeling (H-BIM), parametric modelling, Pompeii, stone pavements.

\section{Introduction}

The acronym H-BIM indicates a new way of modeling the existing structures, generating intelligent models that can contain and manage information, and concern all components of the project, including their geometric and identification information described in detail (Murphy, McGovern \& Pavia, 2009, 2013). The digitization of data relating to historical heritage consists in the creation of a model that represents the virtual copy of the existing one and constitutes a database of information in the most likely way. The aim is to preserve the cultural significance of the artistic asset and to define intervention strategies in an optimal way. In this sense, the BIM model could be a good solution to the management of this type of information, being able to incorporate both quantitative and qualitative data of a certain asset in a structured way, which can be easily extracted if necessary (Antonopoulou, 2017). Furthermore, the fact that many types of information are contained in a single model means that different professional figures can work on the same file (historians, archaeologists, architects, engineers, etc.). In this way, everyone can add their own contribution, without having to repeat work already done by others (for example, repeat a survey if an appropriate one already exists). Bianco, Del Giudice \& Zerbinatti (2013) propose the creation of a web platform with an information system on cultural heritage. The system would allow different access levels; people who can edit data and people who can only view it. This platform should be in line with BIM interoperability principles, allowing users to access the three-dimensional model and data tables. The H-BIM process involves a reverse-engineering solution: in fact, a representation of all the information concerning an existing building is created starting from relevant data (Dore, 2012). This process can be divided into three phases: 1) data acquisition; 2) data processing; 3) data fusion. Many studies have been published on the relief techniques with regard to the comparison and integration of these two methodologies, and many of these focus on applications for historic buildings (Remondino, 2011). The main digital-based and reality-based techniques for data acquisition and producing 3D models can be classified into: a) techniques based 
on passive sensors (image-based methods) (Remondino \& El-Hakim, 2006); b) techniques based on active sensors (range-based methods) (Vosselman \& Maas, 2010). Regarding the image-based methods, photogrammetry is the best known and used for cartographic, architectural, industrial and archaeological surveys, with the precision and reliability of the results as the main objective. A similar technique is the computer vision which, however, has as its primary purpose the automation of the entire return process (2D or 3D) from images, thus reducing the accuracy and results obtained. The range-based methods use instruments that emit an electromagnetic signal (in the field of visible, infrared, X-rays, etc.), which is then recorded by the instrument in order to derive a measurement of distance (range). Range-based tools are laser scanners (terrestrial or airborne), total stations, GNSS, radars, etc. A 3D survey and modeling methodology is designed by combining different techniques, trying to exploit the advantages and overcome any limits of each single technique. In fact, at the moment, there is no single portable and flexible survey technique, capable of providing, at the same time, accurate results at a low cost and in a short time. Therefore, the integration of different survey techniques, especially for terrestrial applications, is generally adopted to detect very complex and wide sites. Once the measurements have been made and the data collected, the model must be created. The availability of 3D data in the form of point clouds is a significant advantage to produce BIM models. The expression "Scan to BIM" is used to describe this process of creating, manipulating and positioning native BIM components on direct reference to an underlying point cloud. This phase involves the design and construction of a parametric library of objects, based on data that can derive from existing treatises and manuals on architecture or from information acquired from the real world (archive data and findings) (Ippolito, 2016; Remondino, 2011). Starting from these data, a library of parametric objects that represent the different components of the artefact is created. These modeled elements will then be merged to obtain a unique virtual representation of the historic building (Guarnieri, Remondino \& Vettore, 2006). For the modeling of existing parametric buildings, which are unique and may have a certain degree of complexity, it is appropriate to evaluate the possibility of using existing libraries or implementing new ones on a case-by-case basis (Oreni, Karimi \& Barazzetti, 2017). Geometric shapes can be created in the BIM model manually, semi-automatically or automatically, based on the point cloud or the triangulated mesh (Lari, Ayman \& Kwak, 2011). The manual method consists in modeling shapes and volumes on the trace of the point cloud. Semi-automatic modeling methodology consists in resorting to libraries of architectural components of historic buildings, which 
through algorithms can be combined automatically to generate facades and models. Then the model is redefined and adapted based on the geometric survey performed with a laser scanner or photogrammetry (Dore \& Murphy, 2015). Some examples of modeling aid tools are the Redstack ScantoBim, Kubit Pointsense, Pointfuse, 3D Rashaper software, which can be integrated with software such as Autodesk Autocad / Autodesk Revit. For the modeling of simple shapes, the available functions of the BIM software can be used; to create complex shapes, parametric objects can be created from the points cloud; while to create unique shapes, complex geometries can be imported, generated via NURBS or B-rep algorithms (Chiabrando, Sammartano \& Spanò, 2016). Once the geometry of all the components of the product has been created and the semantics defined, it is possible to add other relevant data and information, always in a structured way, by associating them with the correct BIM element (Abbondati, Biancardo, Palazzo, Capaldo \& Viscione, 2020; Biancardo, Capano, De Oliveira \& Tibaut, 2020; Biancardo, Viscione, Oreto, Veropalumbo \& Abbondati, 2020; Dell'Acqua, De Oliveira \& Biancardo, 2018). By properly preparing the data, the subsequent extraction of information is facilitated, and the data can be obtained correctly for any subsequent analysis such as structural calculations, lighting engineering, management of the premises, etc. (Conte \& Filippa, 2015). Modeling becomes even more difficult if the deterioration of the object over time is considered. Another feature that differentiates H-BIM from BIM for new buildings is the fact that very often some information is not available. For example, the materials contained in a certain element may be hidden behind a surface coating and the structural and energy characteristics may be unknown. At the last phase of the HBIM process there is the merging of data into a BIM model, including nongraphic information relating to the artefact, from which it is possible to produce all the typical 2D drawings, 3D drawings and documentation for the final purpose (be it a project or management). All the information is contained in the model database and one of the most important aspects is the possibility to query the model, which provides important information on the objects and helps define the types of interventions to be carried out. 


\section{Case study}

\subsection{Territorial context}

Pompeii is a vast archaeological site in the Campania region in Southern Italy (Figure 1). Once a thriving and sophisticated Roman city, Pompeii was buried under meters of ash and pumice from the catastrophic eruption of Mount Vesuvius in 79 AD. Pompeii stands on a buttress about 40 meters high, formed by the flow of a lava flow erupted by Vesuvius in prehistoric times. The land on which the city was built is therefore considerably irregular, with a steep slope towards the south; the flat area is in the western sector, where the first market square and the forum with public buildings opened. The lava front, which stopped on the south side, formed a natural bulwark towards the sea with the sheer wall. The perimeter of the walls, although not entirely excavated, was recognized throughout the extension $(3220 \mathrm{~m})$ and included an inhabited area of the surface of about 66 ha. The roads, almost all straight and crossing at right angles, are divided into main arteries, corresponding to the cardines with direction from North to South and to the decumans with direction from West to East, and in secondary arteries, of variable width; they are flanked by more or less high sidewalks, made with construction waste and paved by private individuals. In order to obtain an in-depth picture of knowledge on the case study, all the information on the site was collected using previous research (Garilli, Autelitano \& Giuliani, 2017; Garilli \& Giuliani, 2019; Poehler \& Crowther, 2018; Poehler, Roggen \& Crowther, 2019).
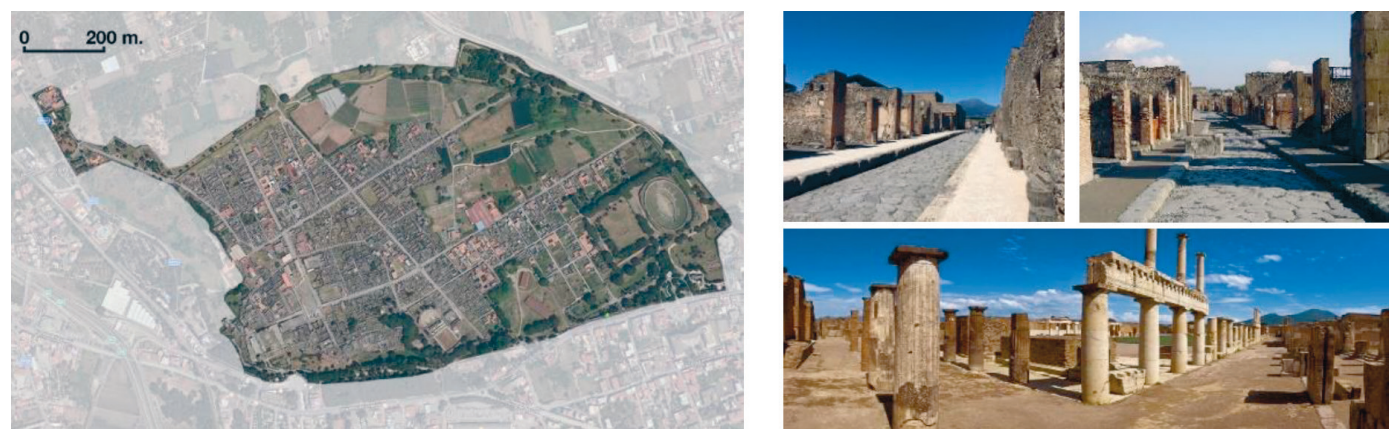

Figure 1. An overview of the archaeological site of Pompeii 


\subsection{GIS-BIM integration}

GIS and BIM integration enables smarter infrastructure. While GIS information is necessary for planning and operating roads, bridges, airports, rail networks, and other infrastructure in the context of their surroundings, BIM information is a key for the design and construction of those structures (Mangon, 2018). Esri and Autodesk, world leaders in geospatial systems and digital design, have launched a technological partnership aimed at creating a "bridge" between their respective leading technologies: the GIS (Geographic Information System) for Esri and BIM (Building Information Model) for Autodesk side. The GIS data available (Poehler \& Crowther, 2018) were imported in BIM model using Autodesk Infraworks. With this tool it is possible to create threedimensional models of a portion of territory, extended up to $200 \mathrm{~km}^{2}$. The model, visually realistic and complete in every detail, is built using all available GIS data: terrain models, orthophotos, survey data, environmental and anthropic data. In this way it was possible to have a preliminary modeling of the entire archaeological area of the Pompeii (Figure 2). By selecting the generic road, geometrical information, modern name of the street, construction period, maintenance treatments, material can be displayed.

\subsection{BIM 4D dimension - paving activity}

Pompeii's pavers were not flat flagstones but were instead either dome- or pyramid-shaped stones with an irregular outline on their flat, top-facing sides. Poehler and Crowther (2018) evidenced the yielded eight phases of paving activity with approximate dates beginning at least in the first decades of the first century B.C.E. and ending on the day of Mt. Vesuvius' eruption in 79 C.E.
Vikroras Vorobjovas,

Gianluca Dell'Acqua

Modeling Roman

Pavements using

Heritage-BIM:

A Case Study in

Pompeii
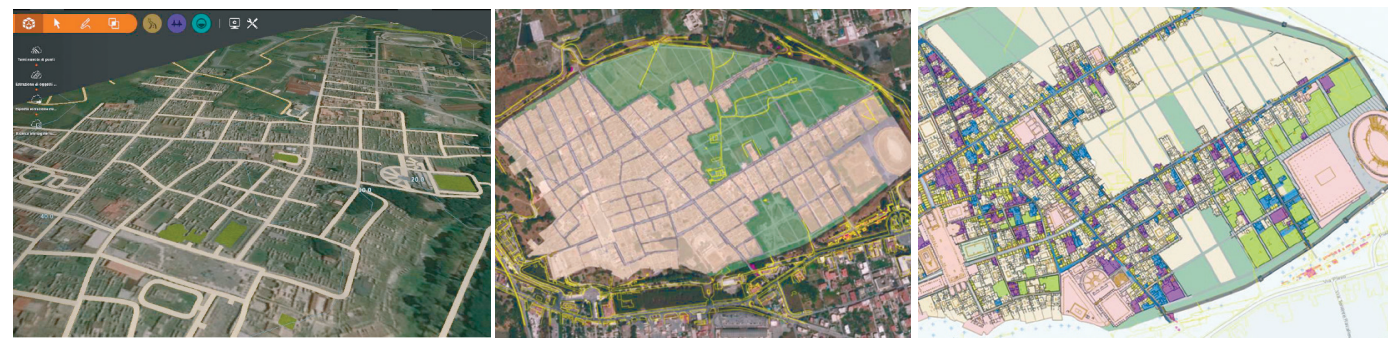

Figure 2. GIS integration in Infraworks BIM tool 
These are:

- Phase 1: Pre-aqueduct period (100-20 B.C.E.);

- Phase 2: Augustan fountain period (20-1 B.C.E.);

- Phase 3: Augustan drainage period (1-20 C.E.);

- Phase 4: Early Imperial period (20-40 C.E.);

- Phase 5: Middle Imperial period (40-62/3 C.E.);

- Phase 6: Post-earthquake(s) period (62/3-79 C.E.);

- Phase 7: Period immediately prior to eruption; new pavement partially laid, but unfinished (79 C.E.);

- Phase 8: Period immediately prior to eruption; street in preparation for repaving (79 C.E.).

The chronology of paving in Pompeii was graphically represented using Navisworks by Autodesk, 4D software for bringing a project plan/schedule and its respective $3 \mathrm{D}$ model together to carry out a simulation. It helps in understanding the sequence of work in a virtual 3D world. Based on interoperability concepts of BIM environmental, the model created with InfraWorks was exported and then imported in Navisworks. The results are shown in Figure 3.

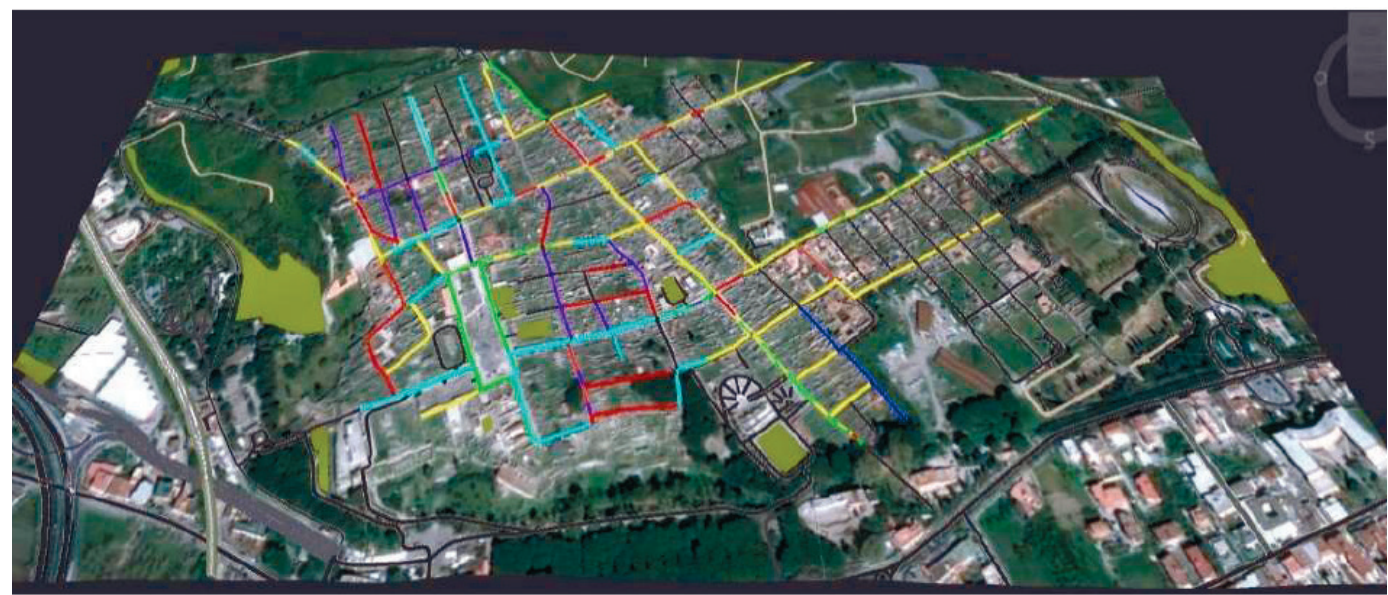

Phase 1: Preaqueduct period (100-20 B.C.E.)

Phase 2: Augustan fountain period (20-1 B.C.E.)

Phase 3: Augustan drainage period (1-20 C.E.)

Phase 4: Early Imperial period (20-40 C.E.)
Phase 5: Middle Imperial period (40-62/3 C.E.)

Phase 6: Post-earthquake(s) period (62/3-79 C.E.)

Phase 7: Period immediately prior to eruption; new pavement partially laid, but unfinished (79 C.E.)

Phase 8: Period immediately prior to eruption; street in preparation for repaving (79 C.E.)

Figure 3. GIS integration in Infraworks BIM tool 


\subsection{Via Del Vesuvio 3D model}

The detailed 3D parametric model was developed for Via Del Vesuvio, which with Via Stabiana represents the hinge connecting Porta Vesuvio to Porta di Stabia (Figure 4). Via del Vesuvio is $91.28 \mathrm{~m}$ long, with an effective area of $282.58 \mathrm{~m}^{2}$. On-site survey was carried out to collect the geometric information. This survey allowed obtaining dimensional confirmations and was one of the inputs of both general and detailed information for the subsequent modeling.

Autodesk's Revit BIM tool, despite mostly used for buildings, was selected as suitable for historic stone pavements, due to the possibility of creating ad-hoc parametric families for each object. The starting point was the generation of DTM through TIN surface using Civil 3D by Autodesk BIM tool. Then, TIN surface was imported into Revit BIM where all the materials and geometric properties were added. According to Poehler and Crowther (2018), the road pavement is characterised by 3 layers (Figure 5): the first foundation layer consisting of gravel and river pebbles, whose function was to ensure the dissipation of the loads coming from the upper layers and drainage of the water; therefore, it represented both the statumen and the the rudus of the classic Roman flooring; the second layer of beaten ash which represented the core; the third layer consisting of sand, which guaranteed regularity of the laying surface, and blocks of lava or basaltic stone dome-shaped and small elements of a ramidale shape that had the function of covering the grooves left during the laying of the boulders. The total thickness of the road turns out to be about $100 \mathrm{~cm}$.
Vikroras Vorobjovas,

Gianluca Dell'Acqua

Modeling Roman

Pavements using

Heritage-BIM:

A Case Study in

Pompeii
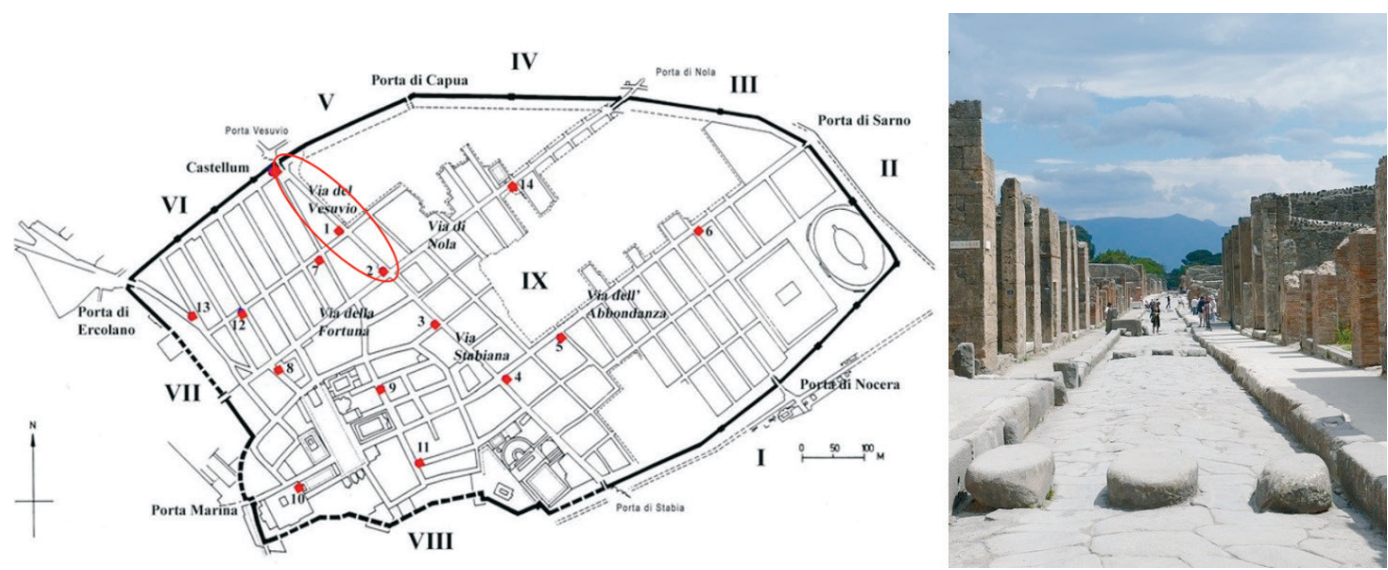

Figure 4. Plan and 3D view of the selected road element Via Del Vesuvio 
Finally, the stones used for pedestrian crossing that can be found throughout the road network of ancient Pompeii, were modeled, using the real dimensions and respecting the spaces that were used for the passage of the wagons as shown in Figure 6.

\section{Conclusions}

In the research, the most appropriate procedure for modeling historic roads was tested, since there were no specific calculation codes for H-BIM. The uniqueness of the archaeological contexts and historic roads is not in itself in line with the strengths of the software created for
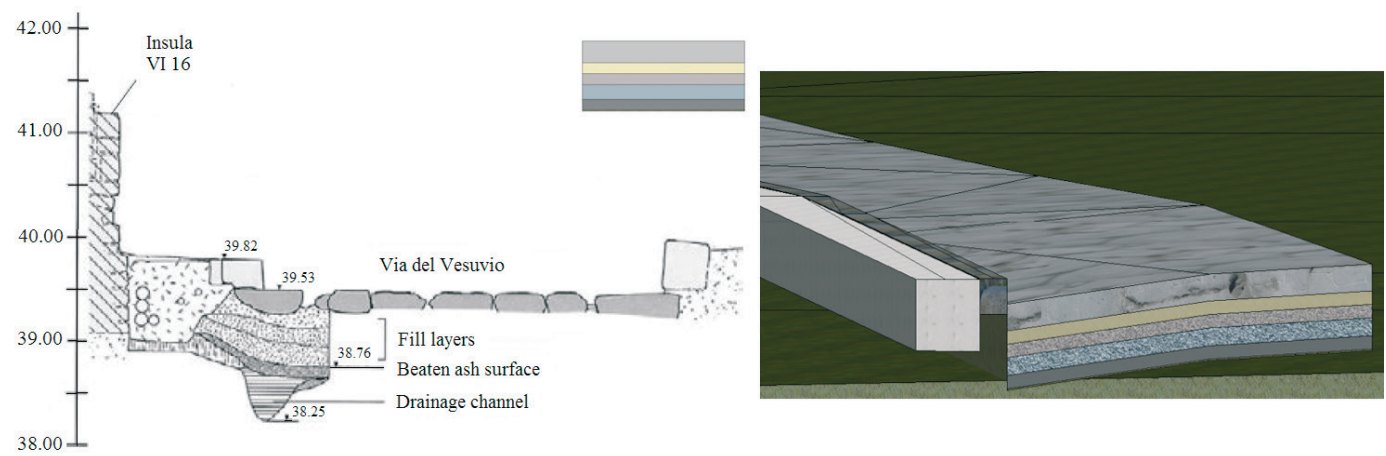

Figure 5. Section of Via del Vesuvio (Seiler, Beste, Piraino \& Esposito, 2005) and its relative $3 D$ visualization
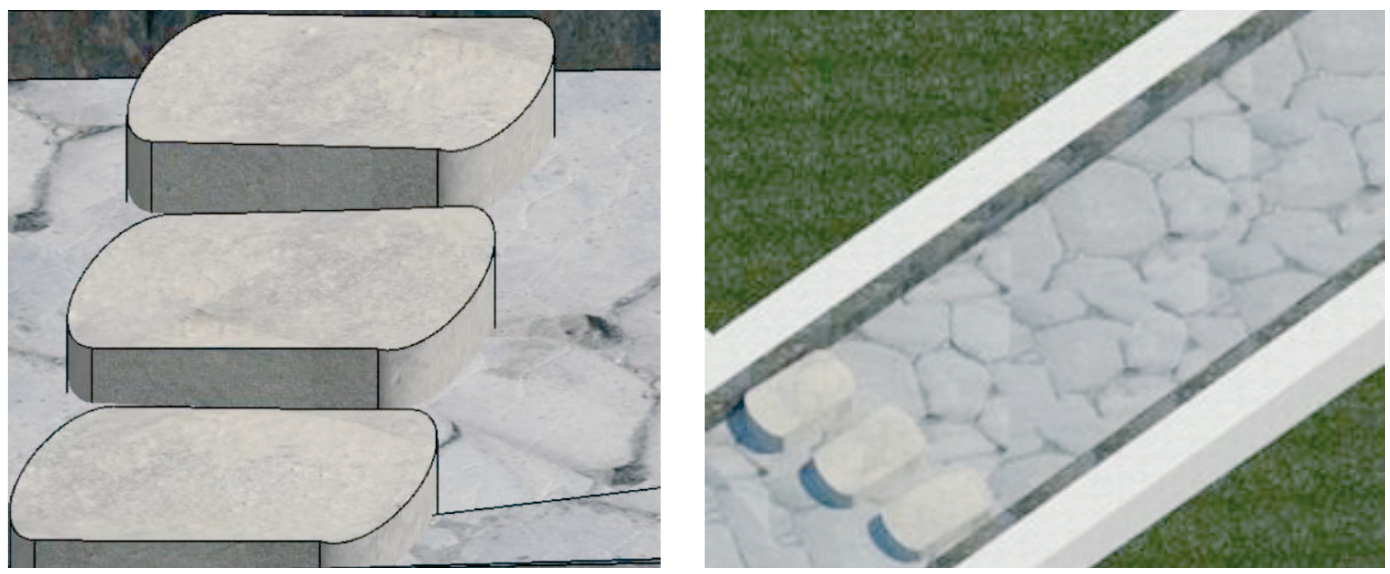

Figure 6. Section of Via del Vesuvio (Seiler, Beste, Piraino \& Esposito, 2005) and its relative $3 \mathrm{D}$ visualization 
seriality and repetition, typical of new buildings. In the case of a study, Vikroras Vorobjovas, it was necessary to create many ad-hoc elements, creating local families specific to this historic building. The advantages of having H-BIM model offers numerous opportunities to optimize the management, maintenance and protection of existing works. Having a digital model of the artefact available allows the protection and promotion bodies of the territory to manage in an optimal way:

- monitoring of degradation, also structural, through a computerized comparison between the data entered in the digital model and the same data detected in real time through sensors;

- planning of restoration interventions;

- protection of information related to the work, which comes into this way preserved through a digital cloud archive;

- simulation of catastrophic events (such as earthquakes bitterly recurrent in Italy).

Adding a better geospatial context to the BIM process means the project owner gets better designs and saves money. With all GIS and BIM information stored in the cloud, stakeholders in both infrastructure and building projects will be able to manage data in any environment in any part of the world, yet reuse and repurpose that information in other contexts without having to continuously convert data.

The 4D dimension, used in this study for representing the phases of paving, can be used for implementing scheduled maintenance treatments with their relative documentation carried out.

The main challenge is inherent in modeling as it is necessary to develop simple methods to obtain BIM models for cultural heritage, which in any case guarantee accuracy, precision and quality of representation consistent with the data acquired through the most innovative detection methods. BIM calculation codes of the Autodesk family were used; therefore, it was experimented how they responded to the import and export of the files between them. For Revit BIM tool, some import problems were detected, as it managed to open only the files in dwg format, without having a loss of geometric attributes.

For future improvements, it will be necessary to carry out highdefinition surveys with the use of drones or laser scanners to obtain the georeferenced point cloud, and consequently a more accurate BIM pavement model, going down to the detail of the single stone. The creation of H-BIM parametric libraries, accessible and free, would surely help practitioners create H-BIM models, facilitating the reuse of historical elements. It would also be very important to create ad-hoc standards for historic construction at the national level (nomenclature, definitions), going to strengthen the tools for the integration of HBIM procedures in public projects. 


\section{Acknowledgement}

The research was developed within the Project of National Interest PRIN 2017 "Stone Pavements. History, Conservation, Valorisation and Design" (20174JW7ZL) financed by the Ministry of Education, University and Research (MIUR) of the Italian Government.

\section{REFERENCES}

Abbondati, F., Biancardo, S. A., Palazzo, S., Capaldo, F. S., \& Viscione, N. (2020). I-BIM for Airport Infrastructures. Transportation Research Procedia, 45, 596-603. https://doi.org/10.1016/j.trpro.2020.03.052

Antonopoulou, S. (2017). BIM for Heritage: Developing a Historic Building Information Model. Historic England. Retrieved from https://historicengland. org.uk/images-books/publications/bim-for-heritage/heag-154-bim-for-heritage/

Biancardo, S. A., Capano, A., Oliveira, S. G., \&Tibaut, A. (2020). Integration of BIM and Procedural Modeling Tools for Road Design. Infrastructures, 5(4), 37. https://doi.org/10.3390/infrastructures5040037

Biancardo, S. A., Viscione, N., Oreto, C., Veropalumbo, R., \& Abbondati, F. (2020). BIM Approach for Modeling Airports Terminal Expansion. Infrastructures, 5(5), 41. https://doi.org/10.3390/infrastructures5050041

Bianco, I, Del Giudice, M., \& Zerbinatti, M. (2013). A Database for the Architectural Heritage Recovery Between Italy and Switzerland. International Archives of the Photogrammetry, Remote Sensing and Spatial Information Sciences, XL-5/W2, 103-108.

https://doi.org/10.5194/isprsarchives-XL-5-W2-103-2013

Chiabrando, F., Sammartano, G., \& Spanò, A. (2016). Historical Building Models and Their Handling via 3D Survey: From Points Clouds to User-Oriented HBIM. In The International Archives of the Photogrammetry, Remote Sensing and Spatial Information Sciences (2016 XXIII ISPRS Congress) (vol. XLI-B5), Czech Republic, Prague, 12-19 July 2016.

https://doi.org/10.5194/isprsarchives-xli-b5-633-2016

Conte, A., \& Filippa, M. (2015). Patrimonio e Siti UNESCO: Memoria, Misura e armonia. Gangemi Editore. ISBN 978-8849-22-728-4, 1024 p.

Dell'Acqua, G., De Oliveira, S. G., \& Biancardo, S. A. (2018). Railway-BIM: Analytical Review, Data Standard and Overall Perspective. Ingegneria Ferroviaria, 73(11), 901-923.

Dore, C., \& Murphy, M. (2012). Integration of Historic Building Information Modeling (HBIM) and 3D GIS for Recording and Managing Cultural Heritage Sites. In The Proceedings of the 18th International Conference on Virtual Systems and Multimedia. Italy, Milan, 2-5 September 2012. https://doi.org/10.1109/VSMM.2012.6365947 
Dore, C., \& Murphy, M. (2015). Historic Building Information Modelling (HBIM). In S. Brusaporci (Ed.) Handbook of Research on Emerging Digital Tools for Architectural Surveying (pp. 233-273). IGI Global. https://doi.org/10.4018/978-1-4666-8379-2.ch007

Garilli, E., Autelitano, F., \& Giuliani, F. (2017). A Study for the Understanding of the Roman Pavement Design Criteria. Journal of Cultural Heritage, 25, 87-93. https://doi.org/10.1016/j.culher.2017.01.002

Garilli, E., \& Giuliani, F. (2019). Stone Pavement Materials and Construction Methods in Europe and North America Between the 19th and 20th Century. International Journal of Architectural Heritage, 13(5), 742-768. https://doi.org/10.1080/15583058.2018.1470269

Guarnieri, A., Remondino F., \& Vettore A. (2006). Digital Photogrammetry and TLS Data Fusion Applied to Cultural Heritage 3D Modeling. In The Proceedings of ISPRS Commission V Symposium, Image Engineering and Vision Metrology, 25-27 September 2006. Retrieved from http://www.isprs.org/proceedings/XXXVI/part5/paper/1216_Dresden06.pdf

Ippolito, A. (Ed.). (2016). Handbook of Research on Emerging Technologies for Architectural and Archaeological Heritage. IGI Global. ISBN 978-1522-50-675-1, 450 p. https://doi.org/10.4018/978-1-5225-0675-1

Lari, Z., Ayman, H., \& Kwak, E. (2011). An Adaptive Approach for Segmentation of 3D Laser Point Cloud. International Archives of the Photogrammetry, Remote Sensing and Spatial Information Sciences, XXXVIII-5/W12, 103-108. https://doi.org/10.5194/isprs-archives-XLII-2-W5-553-2017

Mangon, N. (2018). GIS and BIM Integration Will Transform Infrastructure Design and Construction. Redshift by Auodesk. Retrieved from https://www. autodesk.com/redshift/gis-and-bim-integration/

Murphy, M., McGovern, E., \& Pavia, S. (2009). Historic Building Information (HBIM). Structural Survey, 27(4), 311-327.

https://doi.org/10.1108/02630800910985108

Murphy, M., McGovern, E., \& Pavia, S. (2013). Historic Building Information Modelling - Adding intelligence to Laser and Image Based Surveys of European Classical Architecture. ISPRS Journal of Photogrammetry and Remote Sensing, 76, 89-102. https://doi.org/10.1016/j.isprsjprs.2012.11.006

Poehler, E. E., \& Crowther, B. M. (2018). Paving Pompeii: The Archaeology of Stone-Paved Streets. American Journal of Archaeology 122(4), 579-609. https://doi.org/10.3764/aja.122.4.0579

Poehler, E. E., Roggen, J., \& Crowther, B. M. (2019). The Iron Streets of Pompeii. American Journal of Archaeology, 123(2), 237-262.

https://doi.org/10.3764/aja.123.2.0237

Oreni, D., Karimi, G., \& Barazzetti. L. (2017). Appling BIM to Built Heritage With Complex Shapes: The Ice House of Filarete's Ospedale Maggiore in Milan, Italy. International Archives of the Photogrammetry, Remote Sensing and Spatial Information Sciences, XLII-2/W5, 553-560.

https://doi.org/10.5194/isprs-archives-XLII-2-W5-553-2017

Remondino, F. (2011). Heritage Recording and 3D Modeling With Photogrammetry and 3D Scanning. Remote Sensing, 3(6), 1104-1138.

https://doi.org/10.3390/rs3061104
Salvatore Antonio

Biancardo,

Francesca Russo,

Rosa Veropalumbo,

Vikroras Vorobjovas,

Gianluca Dell'Acqua

Modeling Roman

Pavements using

Heritage-BIM:

A Case Study in

Pompeii 
Remondino, F., \& El-Hakim, S. (2006). Image-Based 3D Modelling: A Review. The Photogrammetric Record, 21(115), 269-291.

https://doi.org/10.1111/j.1477-9730.2006.00383.x

Seiler, F., Beste, H., Piraino, C., \& Esposito, D. (2005). La Regio VI Insula 16 e la zona della Porta Vesuvio. Nuove ricerche archeologiche a Pompei ed Ercolano. Studi della Soprintendenza archeologica di Pompei, 10, 216-234. Electa Napoli.

Vosselman, G., \& Maas, H-G. (2010). Airborne and Terrestrial Laser Scanning. Whittles Pub. 336 p. ISBN 978-1904-44-587-6

\section{Notations}

\section{Abbreviations}

BIM - Building Information Modeling;

DTM - Digital Terrain Model;

H-BIM - Heritage-Building Information Modeling;

NURBS - Non-Uniform Rational Basis Spline;

TIN - Triangulated Irregular Network. 